\title{
Article \\ Thermodynamic Characterization and Equation of State for Solid and Liquid Lead
}

\author{
Nikolay V. Kozyrev *(D) and Vladimir V. Gordeev (D) \\ Laboratory for Physicochemical Fundamentals of Energetic Condensed Systems, Institute for Problems of \\ Chemical and Energetic Technologies, Siberian Branch of the Russian Academy of Sciences (IPCET SB RAS), \\ 659322 Biysk, Russia; gordeev.vladimir92@yandex.ru \\ * Correspondence: kozyrev@ipcet.ru
}

Citation: Kozyrev, N.V.; Gordeev, V.V. Thermodynamic Characterization and Equation of State for Solid and Liquid Lead. Metals 2022, 12, 16. https://doi.org/10.3390/met12010016

Academic Editor: Guy Makov

Received: 19 November 2021

Accepted: 15 December 2021

Published: 22 December 2021

Publisher's Note: MDPI stays neutral with regard to jurisdictional claims in published maps and institutional affiliations.

Copyright: (C) 2021 by the authors. Licensee MDPI, Basel, Switzerland. This article is an open access article distributed under the terms and conditions of the Creative Commons Attribution (CC BY) license (https:// creativecommons.org/licenses/by/ $4.0 /)$.

\begin{abstract}
A high-temperature equation of state (EoS) for the fcc phase of solid lead and liquid lead was developed herein using experimental data on thermodynamic properties, volumetric thermal expansion, compressibility, temperature-dependent bulk modulus, and sound velocity from ultrasonic measurements and melting curve. The whole totality of experimental data was optimized using the temperature-dependent Murnaghan EoS over a pressure range of 0-130 kbar. The temperature dependences of thermodynamic and thermophysical parameters were described herein using an expanded Einstein model. The resultant EoS describes well the whole set of available experimental data within measurement uncertainties of individual parameters.
\end{abstract}

Keywords: equation of state; solid and liquid lead; melting curve; behavior modeling

\section{Introduction}

Thermodynamic and thermophysical properties of lead are a subject matter of numerous experimental and theoretical studies. The experimental data available involve measurements of enthalpy, heat capacity, and thermal expansion at normal pressure over a wide temperature range. For solid lead, the temperature effect on adiabatic bulk modulus and the pressure effect on its density have been explored. For liquid lead, numerous measurements of its density and sound velocity as a function of temperature have been carried out. Information on the phase diagram in the vicinity of high pressures and temperatures has also been made public. A variety of equations of state (EOS) have been suggested for different phase modifications of solid lead and describe their behaviors satisfactorily over a wide range of pressure- and temperature-related variations. However, a similar wide-range equation of state for liquid lead is lacking so far, which would predict liquid lead properties over a pressure range of practical importance, at least up to $100 \mathrm{kbar}$, when the temperature changes from the melting to the boiling point [1].

Apart from thermodynamic properties, only two parameters have been measured for liquid metals by now: the temperature dependence of volume (thermal expansion) and sound velocity from which adiabatic and isothermal bulk compression moduli can be estimated. Based on these data, it is impossible to build a strict equation of state, as the liquid phase compressibility is unknown. However, if the pressure dependence of melting temperature is used as additional data, there occurs one more limitation on the liquid phase properties because the chemical potentials of the solid and liquid phases are equal at the point of melting. In such a case, there appears a possibility to find the equation of state for liquid metals through the means of a simultaneous solution of the system of thermodynamic and thermophysical equations for solid and liquid phases at a time. To check this possibility, we chose lead whose properties have been studied in sufficient detail for both solid and liquid phases.

The present study aimed to perform complete thermodynamic and thermophysical characterization of the solid and liquid phases of lead, given the latest experimental data, 
and construct a wide-range equation of state for liquid lead using the findings. Since only properties of the face-centered cubic (fcc) structure of solid lead have been studied in sufficient detail to date, and only individual parameters have been measured for the hexagonal close-packed (hcp) and body-centered cubic (bcc) phases, the present study is confined to examining the fcc solid phase and molten lead.

\section{Physicochemical Model}

The thermodynamic parameters were optimized herein taking into account the recommendations reported [2], on the basis of the expanded Einstein model using multiple functions similar to those described in [3]. An analogous model was used to describe the thermal expansion of solid lead. As is shown [4], such a functional form with a different number of terms approximates well experimental data for a wide array of crystal materials.

\subsection{Thermodynamic Functions}

Different types of functions were employed to describe the thermodynamic properties of solid and liquid lead in the standard state because temperature-dependent variations in the heat capacity of these phases are dramatically different. For solid lead, a threeterm Einstein equation was used with a correction power extra term in order to consider anharmonic effects. Thermodynamic functions of solid lead at zero pressure were adopted in the following form:

$$
\begin{gathered}
H_{T}-H_{0}=\sum_{i=1}^{3} \frac{Y_{i} \theta_{i}}{\exp \left(\theta_{i} / T_{i}\right)-1}+h T^{m} \\
C_{P}=\frac{d H_{T}}{d T}=\sum_{i=1}^{3}\left(\frac{\theta_{i}}{T}\right)^{2} \frac{Y_{i} \exp \left(\theta_{i} / T\right)}{\left[\exp \left(\theta_{i} / T\right)-1\right]^{2}}+m h T^{m-1} \\
S=\Delta S_{0}+\sum_{i=1}^{3} Y_{i}\left\{\frac{\theta_{i}}{T} \frac{\exp \left(\theta_{i} / T\right)}{\exp \left(\theta_{i} / T\right)-1}-\ln \left[\exp \left(\theta_{i} / T\right)-1\right]\right\}+\frac{m}{m-1} h T^{m-1}
\end{gathered}
$$

where $T$ is the temperature, $\mathrm{H}$ is the enthalpy, $C_{P}$ is the heat capacity, $S$ is the entropy, $Y_{i}, \theta_{i}$, $A$ and $m$ are the constants, and $\Delta S_{0}$ is the integration constant.

The variation in the heat capacity of liquid lead with temperature has a complex nature. Starting from the melting point, the heat capacity declines, reaches its minimum, and then begins to rise slowly. Several equations have been proposed for the approximation of heat capacity. For instance, Sobolev et al. [5] suggested the following relationship over a temperature range of $600-2000 \mathrm{~K}$ :

$$
C_{P}=\left(\frac{d H}{d T}\right)_{P_{\circ}}=a+b T+c T^{2}+d T^{-2}
$$

Arblaster [6] used a quadratic equation with a temperature range divided into two intervals from 600.612 to $1500 \mathrm{~K}$ and from 1500 to $2400 \mathrm{~K}$ as follows:

$$
C_{P}=a-b T+c T^{2}
$$

In the present study, the thermodynamic functions for liquid lead were adopted in the following form:

$$
\begin{gathered}
H_{T}-H_{0}=a T^{2}+b T^{1.5}+c T+d T^{0.5}+e \\
C_{P}=\left(\frac{d H}{d T}\right)_{P}=2 a T+1.5 b T^{0.5}+c+0.5 \frac{d}{T^{0.5}} \\
S=2 a T+3 b T^{0.5}+c \ln T-d T^{-0.5}+c_{0}
\end{gathered}
$$

where $a, b, c, d, e$, and $c_{0}$ are the constants. 
The molar Gibbs energy (chemical potential $\mu^{\circ}$ ) at standard pressure $P^{\circ}=0.1 \mathrm{MPa}$ is determined by the common relation:

$$
G_{m} \equiv \mu^{\circ}=\left[H_{T}-H_{0}\right]-T S
$$

\subsection{Description of Molar Volume}

The Tait equation was used to describe the pressure-dependent molar volume of solid and liquid lead $[7,8]$. This equation provides a good approximation of density data for solid and liquid substances at pressures of up to a few GPa [8]. Hansen [9] employed this equation to approximate densities of liquid metals $(\mathrm{Pb}, \mathrm{Hg}, \mathrm{Sn}, \mathrm{Bi})$ depending on melting points at temperatures of up to $923 \mathrm{~K}$ under comparatively low pressures, not above $3 \mathrm{kbar}$. Here, we adopted the following high-temperature form of the Tait equation [7,9]:

$$
P=\frac{B_{T}}{n_{0}+1}\left\{\exp \left[\left(n_{0}+1\right)\left(1-\frac{V}{V_{T}}\right)\right]-1\right\}
$$

where $P$ is the pressure, $V$ is the volume, $V_{T}$ and $B_{T}$ are the molar volume and isothermal bulk modulus at zero pressure and temperature $T$, respectively, and $n_{0}$ is the derivative of the bulk modulus with respect to pressure. The temperature effect on molar volume $V$ was described via the temperature dependences $V_{T}$ and $B_{T}$.

The isothermal bulk modulus for both solid and liquid lead was adopted as an inverse quadratic relationship similar to that in Dinsdale's study [10].

$$
B_{T}=\frac{B_{0}}{1+B_{1} T+B_{2} T^{2}}
$$

where $B_{0}$ is the bulk modulus at $P=0$, and $T=0$.

The temperature-dependent molar volume of solid and liquid lead was described herein by different equations. To describe the thermal expansion of solid lead over a wide temperature range, a relationship similar to that for enthalpy was adopted [1]:

$$
\ln \left(\frac{V_{T}^{S}}{V_{0}^{S}}\right)=\sum_{i=1}^{3} \frac{X_{i} \Theta_{i}}{\exp \left(\Theta_{i} / T_{i}\right)-1}+g T^{k}
$$

where $V_{T} S$ is the molar volume at zero pressure and temperature $T, V_{0} S$ is the molar volume at $P=0$ and $T=0$, and $X_{i}, \Theta_{i}, g$, and $k$ are the constants.

The following equation was used for the molar volume of liquid lead:

$$
V_{T}^{L}=\frac{V_{0}^{L}}{1+A_{1} T+A_{2} T^{2}+A_{3} T^{3}}
$$

where $V_{0}{ }^{L}$ is the "hypothetical" molar volume of liquid lead at zero pressure and zero temperature; $A_{1}, A_{2}$, and $A_{3}$ are the constants.

The melting point of lead $\left(T_{m}\right)$ was assumed equal to $600.612 \pm 0.001 \mathrm{~K}$ in line with the recommendations [11] that rely on precision measurements of lead with a $99.9999 \%$ purity [12].

\subsection{Melting Curve}

The chemical potentials (molar Gibbs energy) of solid $\left(\mu^{S}\right)$ and liquid $\left(\mu^{L}\right)$ phases in the melting curve must be equal [13].

$$
\mu^{S}=\mu^{L}
$$


The relationship between the chemical potential of condensed substances and pressure is determined by the adopted equation of state via the following expression [13]:

$$
\Delta \mu=\int_{P^{\circ}}^{P} V d P
$$

This pressure correction can be estimated by integration of Equation (10). The melting point at each pressure is determined by a simultaneous solution of Equations (9), (14) and (15) for solid and liquid phases.

\section{Selected Experimental Data}

\subsection{Thermodynamic Properties}

The thermodynamic properties of lead were discussed in several reference books and review papers (Table 1$)$. Isobaric heat capacities $\left(C_{P}\right)$ over a temperature range from $100 \mathrm{~K}$ to the melting point of lead reported in different literature sources are well consistent with each other and differ by less than $1 \%$. The difference in other thermodynamic functions within this temperature range is considerably smaller. The most complete and detailed overview of the literature data on thermodynamic properties of solid lead was reported in Arblaster's study [6] that was taken as a basis herein.

Table 1. Reference sources and review sources of data on heat capacity of solid and liquid lead ( $\left.C_{P}, \mathrm{~J} \cdot \mathrm{mol}^{-1} \cdot \mathrm{K}^{-1}\right)$.

\begin{tabular}{ccccc}
\hline \multirow{2}{*}{$\Delta T(\mathbf{K})$} & \multicolumn{2}{c}{ Solid } & Liquid & \multirow{2}{*}{ Refs. } \\
\cline { 2 - 4 } & $C_{\boldsymbol{P}} \mathbf{( 2 9 8 . 1 5 )}$ & $C_{\boldsymbol{P}}\left(\boldsymbol{T}_{\boldsymbol{m}}\right)$ & $\boldsymbol{C}_{\boldsymbol{P}}\left(\boldsymbol{T}_{m}\right)$ & \\
\hline $298.15-1800$ & 26.61 & 29.40 & 30.58 & [14] (Robie, 1978) \\
\hline $100-3600$ & 26.650 & 29.742 & 30.627 & [15] (Glushko, 1982) \\
\hline $298-2000$ & 26.652 & 29.414 & 30.627 & [16] (Pankratz, 1984) \\
\hline $298.15-2019$ & 26.835 & 29.410 & 30.671 & [17] (Barin, 1995) \\
\hline $298-1800$ & 26.65 & 29.74 & 30.63 & [18] (Robie, 1995) \\
\hline $0-3000$ & 26.836 & 29.414 & 30.627 & [19] (Chase, 1998) \\
\hline $600.6-1500$ & - & - & 30.62 & [20] (Sobolev, 2007) \\
\hline $600.6-2000$ & - & - & 30.7 & [5] (Sobolev, 2008) \\
\hline $600.6-2000$ & - & - & 30.621 & [1] (Sobolev, 2010) \\
\hline $0.5-2400$ & 26.492 & 30.062 & 30.817 & [6] (Arblaster, 2012) \\
\hline
\end{tabular}

The data, presented in the reference books and review papers, on the heat capacity of liquid lead (Table 1) over a temperature range between the melting point and $1400 \mathrm{~K}$ are in relatively good agreement with each other. A considerable difference is, however, observed at higher temperatures, which is explained by the lack of sufficiently accurate experimental data at higher temperatures.

In Chase's reference book [19], the heat capacity values for liquid lead were derived by graphical extrapolation of the data [21] to its boiling point. For the estimation of thermodynamic functions, Arblaster [6] used theoretical calculation results [22] based on which the $1500 \mathrm{~K}$ value was considered as the temperature of minimum heat capacity. The heat capacities reported in [6] at temperatures above $1500 \mathrm{~K}$ differ considerably from those reported in other studies and seem to be overestimated. For instance, the difference attains $12-16 \%$ at $2400 \mathrm{~K}$, compared with the data reported in $[15,19]$. Here, we used Glushko's data [15] to optimize the thermodynamic properties of liquid lead. 


\subsection{Thermodynamic Properties of Solid Lead}

In constructing the equation of state for solid lead, the measured data on thermal expansion, isothermal compressibility, and adiabatic bulk modulus were employed. The isothermal bulk modulus included in the equation of state is estimated by the following common relation [1]:

$$
B_{T}=\left(\frac{1}{B_{S}}+\frac{T V \alpha^{2}}{C_{P}}\right)^{-1}
$$

where $B_{S}$ is the adiabatic bulk modulus, and $\alpha$ is the volumetric thermal expansion coefficient.

\subsubsection{Molar Volume}

As some studies report relative values of the sample length or volume rather than the absolute ones, a baseline value of the molar volume of lead at standard temperature should be found. Data on volumetric properties of lead at room temperature are listed in Table 2. In the case in which volumetric properties of lead are represented by unit cell density or parameter in the original literature source, they were used to calculate the molar volume. For comparative purposes, the said parameters are quoted for all the literature sources. All data were reduced to the same temperature of $298.15 \mathrm{~K}$ and, if necessary, recalculated from kX units into $\AA$ in line with Arblaster's study [23]. The average molar volume calculated from the data given in Table 2 was $18.269 \pm 0.004 \mathrm{~cm}^{3} / \mathrm{mol}$.

Table 2. Lattice parameter (a), density and molar volume of lead with a face-centered cubic (fcc) lattice at room temperature.

\begin{tabular}{|c|c|c|c|}
\hline$a(\AA)$ & $\rho\left(\mathrm{g} / \mathrm{cm}^{3}\right)$ & $V_{m}\left(\mathrm{~cm}^{3} / \mathrm{mol}\right)$ & Refs. \\
\hline 4.9499 & 11.348 & 18.270 & [24] (Owen, 1933) \\
\hline 4.9497 & 11.349 & 18.263 & [25] $(\mathrm{Lu}, 1941)$ \\
\hline 4.9511 & 11.340 & 18.272 & [26] (Klug, 1946) \\
\hline 4.95032 & 11.3448 & 18.2718 & [27] (Straumanis, 1949) \\
\hline 4.9505 & 11.344 & 18.266 & [28] (Swanson, 1953) \\
\hline 4.9509 & 11.341 & 18.270 & [29] (Feder, 1958) \\
\hline 4.9508 & 11.342 & 18.269 & [30] (Takahashi, 1969) \\
\hline 4.9505 & 11.342 & 18.268 & [31] (Kramer, 1972) \\
\hline 4.9507 & 11.342 & 18.268 & [32] (Vold, 1977) \\
\hline 4.9510 & 11.340 & 18.271 & [33] (Mao, 1990) \\
\hline 4.9502 & 11.346 & 18.262 & [34] (Vohra, 1990) \\
\hline 4.9503 & 11.345 & 18.271 & [35] (Khairulin, 1992) \\
\hline 4.9510 & 11.34 & 18.272 & [36] (Trunin, 2001) \\
\hline 4.9510 & 11.340 & 18.272 & [37] (Bogoslovskaya, 2002) \\
\hline 4.9502 & 11.346 & 18.262 & [38] (Lubarda, 2003) \\
\hline 4.9510 & 11.3400 & 18.272 & [39] (Rothman, 2005) \\
\hline 4.9510 & 11.3400 & 18.272 & [40] (Stankus, 2006) \\
\hline 4.9513 & 11.338 & 18.275 & [41] (Strassle, 2014) \\
\hline 4.9507 & 11.341 & 18.269 & Average \\
\hline
\end{tabular}

Note: The highlighted data are derived from the cited literature; the other data were obtained by recalculation.

\subsubsection{Thermal Expansion}

The data on the thermal expansion of solid lead can be found in several reference books [42-44]. Here, we used the measured data from earlier studies [45-51] overviewed by Touloukian et al. [45] and from more recent studies [36,41], and these data were coprocessed altogether. The measurement results reported [52] were disregarded because these are significantly distinct from those of the other authors, which is probably due to a low initial lead density of $11.2566 \mathrm{~g} / \mathrm{cm}^{3}$ at $293 \mathrm{~K}$ (Table 2).

\subsubsection{Isothermal Compressibility}

The isothermal compressibility of solid lead was examined in a series of studies [33,34,41,42,53-59]. Bridgman measured the compressibility of solid lead at pres- 
sures ranging from 5 to $25 \mathrm{~kg} / \mathrm{cm}^{2}$ [54] and from 10 to $100 \mathrm{~kg} / \mathrm{cm}^{2}$ [53]. The compressibility data of lead at room temperature and pressures of up to $45 \mathrm{kbar}$ and $100 \mathrm{kbar}$ were reported by Vaidya et al. [56] and Gray [42], respectively. Some studies investigated the compressibility of lead at several temperatures: at 293 and $396 \mathrm{~K}(0-30 \mathrm{kbar})$ [55], and at 298 (0.3-87.4 kbar) and $80 \mathrm{~K}$ (0.6-89 kbar) [41]. A series of studies were concerned with examining phase transitions of solid lead under isothermal compression. Mao et al. [33,57] explored the phase transition of lead from the face-centered cubic (fcc) structure to the hexagonal close-packed (hcp) system at a pressure of $140 \mathrm{kbar}$ and further to the bodycentered cubic (bcc) arrangement at pressures above $1000 \mathrm{kbar}$. Vohra et al. [34] quantified compressibility and phase transitions of lead at pressures of up to $272 \mathrm{GPa}$. The experimental findings were processed separately for all of the three phases. Kuznetsov et al. [59] constructed a $P, T$ phase diagram for lead using synchrotron XRD measurement data at pressures of up to $40 \mathrm{GPa}$ and temperatures of up to $800 \mathrm{~K}$ in the vicinity involving the fcc-to-hcp phase transition. Liu et al. [60] theoretically investigated the phase transitions of lead at high pressure using the first-principles, pseudopotential total-energy method.

\subsubsection{Adiabatic Bulk Modulus}

The adiabatic bulk modulus of solid lead was estimated herein from the measurements reported in the studies $[32,61,62]$ in which elastic moduli of lead were quantified at temperatures ranging from 300 to $600 \mathrm{~K}$ [32], from 3.2 to $300 \mathrm{~K}$ [61], and at 195 and $296 \mathrm{~K}$ [62].

\subsection{Liquid Lead}

There are no directly measured data on isothermal compressibility and bulk modulus of liquid lead in the literature. Therefore, the measurement results of thermal expansion and sound velocity were used herein. The adiabatic bulk modulus was estimated by the following equation [1]:

$$
B_{S} \equiv-V\left(\frac{d P}{d V}\right)_{S}=\rho u_{S}^{2}
$$

where $\rho$ is the density and $u_{S}$ is the sound velocity. The isothermal bulk modulus as part of the equation of state was calculated by Equation (16).

\subsubsection{Thermal Expansion}

There exist a vast number of studies (more than 45 ) on measuring the temperaturedependent density of liquid lead. Some of those were analyzed in the review papers $[1,63,64]$ and are not presented herein. In all of the reviews, the temperature-dependent density of liquid lead was approximated by linear function as follows:

- $\rho=11,420-1.242 \cdot \mathrm{T}$ [63];

- $\rho=11,441-1.2795 \cdot \mathrm{T}[1]$

- $\rho=11,400-1.239 \cdot \mathrm{T}[64]$.

However, most of the studies were left out of account in the aforesaid reviews and hence disregarded in constructing the approximate relationships. The disregarded studies are listed in Table 3. 
Table 3. Supplementary experimental data on density of liquid lead.

\begin{tabular}{|c|c|c|c|c|}
\hline$\Delta T(\mathrm{~K})$ & Purity (\%) & Form $^{a}$ & $\Delta \rho^{\mathrm{b}}$ & Refs. \\
\hline 623.15-923.15 & - & $\mathrm{T}$ & - & [65] (Flinn, 1971) \\
\hline $657.15-824.15$ & 99.999 & $\mathrm{E}$ & $\sim 0.5$ & [66] (Schwaneke, 1978) \\
\hline $600-1100$ & 99.999 & $\mathrm{P}, \mathrm{E}$ & \pm 0.5 & [67] (Saar, 1987) \\
\hline $615 ; 1160$ & - & $\mathrm{D}$ & - & [68] (Mentz-Stern, 1989) \\
\hline 616.15-1286.15 & 99.9 & $\mathrm{~T}$ & \pm 0.1 & [69] (Hansen, 1989) \\
\hline 613.15-1213.15 & - & $\mathrm{P}, \mathrm{E}$ & 0.5 & [70] (Tsuchiya, 1990) \\
\hline 616.15-1286.15 & 99.9 & $\mathrm{~T}, \mathrm{E}$ & \pm 0.1 & [71] (Hansen, 1990) \\
\hline $600.7-1600$ & 99.992 & $\mathrm{~T}$ & $0.3-0.5$ & [35] (Khairulin, 1992) \\
\hline 604-1044 & 99.99 & $\mathrm{P}, \mathrm{E}$ & 0.05 & [72] (Wang, 2003) \\
\hline $623.1-773.1$ & 99.9985 & $\mathrm{~T}, \mathrm{E}$ & 0.2 & [73] (Alchagirov, 2003) \\
\hline $604.7-745.5$ & 99.99 & $\mathrm{~T}, \mathrm{E}$ & 0.1 & [74] (Alchagirov, 2003) \\
\hline $604.4-1702.6$ & 99.99 & $\mathrm{~T}, \mathrm{E}$ & 0.4 & [52] (Stankus, 2004) \\
\hline $573-773$ & - & E & 0.1 & [75] (Kurshev, 2005) \\
\hline $600.1-1500$ & 99.9985 & $\mathrm{~T}, \mathrm{E}$ & $0.2-0.3$ & [76] (Stankus, 2007) \\
\hline $600.55-773.15$ & 99.998 & $\mathrm{~T}, \mathrm{E}$ & 0.2 & [77] (Alchagirov, 2007) \\
\hline $600.7-1100$ & 99.99 & E & $0.3-0.5$ & [78] (Khairulin, 2008) \\
\hline $600.6-1173$ & 99.999 & $\mathrm{P}, \mathrm{E}$ & 0.1 & [79] (Kanchukoev, 2009) \\
\hline 604-1703 & 99.9996 & E & 0.2 & [80] (Popel, 2011) \\
\hline $874-1274$ & 99.9985 & T, E, P & 0.76 & [81] (Shevchenko, 2011) \\
\hline $874-1274$ & 99.9985 & $\mathrm{~T}, \mathrm{E}, \mathrm{P}$ & 0.760 & [82] (Chentsov, 2012) \\
\hline $600.6-1100$ & 99.9999 & E, P & 1 & [83] (Kashezhev, 2012) \\
\hline $601-1100$ & 99.99 & E & 0.3 & [84] (Khairulin, 2013) \\
\hline $600.6-1100$ & - & $\mathrm{E}$ & - & [85] (Kambolov, 2014) \\
\hline
\end{tabular}

a Form of data: D—individual measurements; E-equation; P-plot; T-table. ${ }^{\mathrm{b}}$ Reported error (\%).

For the calculation of thermal expansion of liquid lead, the present study used experimental data from primary sources outlined in review papers $[1,20,63,64]$, and these were supplemented with measurement results from studies listed in Table 3 and from Hansen's study [9]. Hansen [9] performed volumetric measurements of liquid lead over a temperature range of $669-921 \mathrm{~K}$ at elevated pressures of up to $3 \mathrm{kbar}$, with an error of $\pm 0.2 \%$.

\subsubsection{Sound Velocity}

There is a considerable number of studies on measuring the sound velocity in liquid lead particles. Most of the studies were discussed in review papers $[1,20,63,86]$. For simultaneous processing, we used data from studies outlined in the aforementioned reviews, supplemented with measurement results from the other reports [65,70,81,87-90]. All the measurements of the sound velocity in liquid lead samples were performed at temperatures of at most $~ 1400 \mathrm{~K}$. Hixson et al. [91] measured the density-dependent sound velocity in solid and liquid lead samples at a pressure of $0.13 \mathrm{kbar}$. As an optical pyrometer was not available, the samples' temperatures were not measured; instead, temperatures were calculated through approximation of the data reported [92]. Therefore, the data from the study in [92] were not employed for optimization. 


\subsection{Melting Curve}

The fcc-hcp phase transition pressure for the solid phase of lead at room temperature is $134 \pm 6 \mathrm{kbar}$, as recommended in [93]. Given the data reported in the study by Kuznetsov et al. [59], who investigated the phase diagram of lead at pressures below 400 kbar and temperatures below $800 \mathrm{~K}$, the pressure of the fcc-hcp-liquid triple point was assumed to be equal to $130 \mathrm{kbar}$. Therefore, it is this pressure to which all the parameters of the fcc phase of solid lead were optimized.

The melting curve of lead has experimentally been examined at pressures of up to 5 kbar [94], 14 kbar [95], $60 \mathrm{kbar}$ [96,97], 79 kbar [98], 120 kbar [99], and $800 \mathrm{kbar}$ [100]. McDaniel et al. [94] and Dewaele et al. [100] approximated the measured data via Simons' equation. The melting curve of lead has also been studied theoretically at pressures below 1000 kbar [101,102].

\section{Calculation Procedure}

The error function representing a weighted root-mean-squared deviation was adopted as an optimization criterion as follows:

$$
R=\sqrt{\frac{1}{N}\left[\sum_{i=1}^{N} w_{D}^{2}\left(\frac{D_{i}^{c}-D_{i}^{m}}{D_{i}^{m}}\right)^{2}\right]}
$$

where $N$ is the total number of experimental points; $D_{i}$ is the values of different parameters (enthalpy, heat capacity, molar volume, etc.); $w_{i}$ is the weighting coefficients of these parameters. Superscripts $c$ and $m$ denote the calculated and measured properties, respectively. The weighting coefficients were evaluated based on relative errors in the measurement of different parameters.

The function was minimized via the Nelder-Mead simplex method for multidimensional minimization [103].

\section{Results}

The parameters obtained by optimization for the fcc phase of solid lead are listed in Table 4. Table 5 shows parameters for liquid lead. At the melting temperature, the calculated isothermal bulk moduli for solid and liquid lead are $335.03 \mathrm{kbar}$ and $300.77 \mathrm{kbar}$, respectively. The lower bulk moduli value for liquid lead evinces its high compressibility, as one should expect.

Table 4. Summation of optimized parameters of EoS for the fcc phase of solid lead.

\begin{tabular}{|c|c|c|}
\hline \multicolumn{2}{|c|}{ Equation, Parameter } & Value \\
\hline \multirow{9}{*}{ Thermodynamic functions (1)-(3) } & $\Upsilon_{1}$ & 0.612185 \\
\hline & $\Upsilon_{2}$ & 16.0473 \\
\hline & $\Upsilon_{3}$ & 9.08323 \\
\hline & $\theta_{1}, \mathrm{~K}$ & 17.6535 \\
\hline & $\theta_{2}, \mathrm{~K}$ & 50.0926 \\
\hline & $\theta_{3}, \mathrm{~K}$ & 119.641 \\
\hline & $\Delta S_{0}, \mathrm{~J} \cdot \mathrm{mol}^{-1} \cdot \mathrm{K}^{-1}$ & 0.035200 \\
\hline & $h, \mathrm{~K}^{-m}$ & $4.85078 \times 10^{-7}$ \\
\hline & $m$ & 3.31693 \\
\hline Equation of state (10) & $n_{0}$ & 5.25202 \\
\hline \multirow{3}{*}{ Bulk modulus (11) } & $B_{0}$, kbar & 489.03 \\
\hline & $B_{1}, \mathrm{~K}$ & $3.8676 \times 10^{-4}$ \\
\hline & $B_{2}, \mathrm{~K}$ & $6.3173 \times 10^{-7}$ \\
\hline
\end{tabular}


Table 4. Cont.

\begin{tabular}{|c|c|c|}
\hline \multicolumn{2}{|c|}{ Equation, Parameter } & Value \\
\hline \multirow{9}{*}{ Thermal expansion (12) } & $V_{0}{ }^{S}, \mathrm{~cm}^{3} / \mathrm{mol}$ & 17.8754 \\
\hline & $X_{1}$ & $6.3894 \times 10^{-5}$ \\
\hline & $X_{2}$ & $2.1486 \times 10^{-5}$ \\
\hline & $X_{3}$ & $1.1473 \times 10^{-4}$ \\
\hline & $\Theta_{1}, \mathrm{~K}$ & 71.1214 \\
\hline & $\Theta_{2}, \mathrm{~K}$ & 1949.26 \\
\hline & $\Theta_{3}, \mathrm{~K}$ & 4117.35 \\
\hline & $g, \mathrm{~K}^{-k}$ & $2.0082 \times 10^{-6}$ \\
\hline & $k$ & 1.36326 \\
\hline
\end{tabular}

Table 5. Summation of optimized parameters of EoS for liquid lead.

\begin{tabular}{|c|c|c|}
\hline \multicolumn{2}{|c|}{ Equation, Parameter } & Value \\
\hline \multirow{6}{*}{ Thermodynamic functions (6)-(9) } & $a, \mathrm{~J} \cdot \mathrm{mol}^{-1} \cdot \mathrm{K}^{-2}$ & $6.23666 \times 10^{-3}$ \\
\hline & $b, \mathrm{~J} \cdot \mathrm{mol}^{-1} \cdot \mathrm{K}^{-1.5}$ & -0.751793 \\
\hline & $c, \mathrm{~J} \cdot \mathrm{mol}^{-1} \cdot \mathrm{K}^{-1}$ & 58.1052 \\
\hline & $d, \mathrm{~J} \cdot \mathrm{mol}^{-1} \cdot \mathrm{K}^{-0.5}$ & -354.600 \\
\hline & $e, \mathrm{~J} \cdot \mathrm{mol}^{-1}$ & 2843.67 \\
\hline & $c_{0}, \mathrm{~J} \cdot \mathrm{mol}^{-1} \cdot \mathrm{K}^{-1}$ & 245.951 \\
\hline Equation of state (10) & $n_{0}$ & 5.59745 \\
\hline \multirow{3}{*}{ Bulk modulus (11) } & $B_{0}$, kbar & 451.01 \\
\hline & $B_{1}, \mathrm{~K}$ & $5.8382 \times 10^{-4}$ \\
\hline & $B_{2}, \mathrm{~K}$ & $4.1329 \times 10^{-7}$ \\
\hline \multirow{4}{*}{ Thermal expansion (13) } & $V_{0}^{L}, \mathrm{~cm}^{3} / \mathrm{mol}$ & 18.2152 \\
\hline & $\mathrm{A}_{1}, \mathrm{~K}^{-1}$ & $-1.0094 \times 10^{-4}$ \\
\hline & $\mathrm{A}_{2}, \mathrm{~K}^{-2}$ & $-4.6828 \times 10^{-9}$ \\
\hline & $\mathrm{A}_{3}, \mathrm{~K}^{-3}$ & $5.6664 \times 10^{-13}$ \\
\hline
\end{tabular}

Comparisons between the calculated and measured data are given in Figures 1-10.

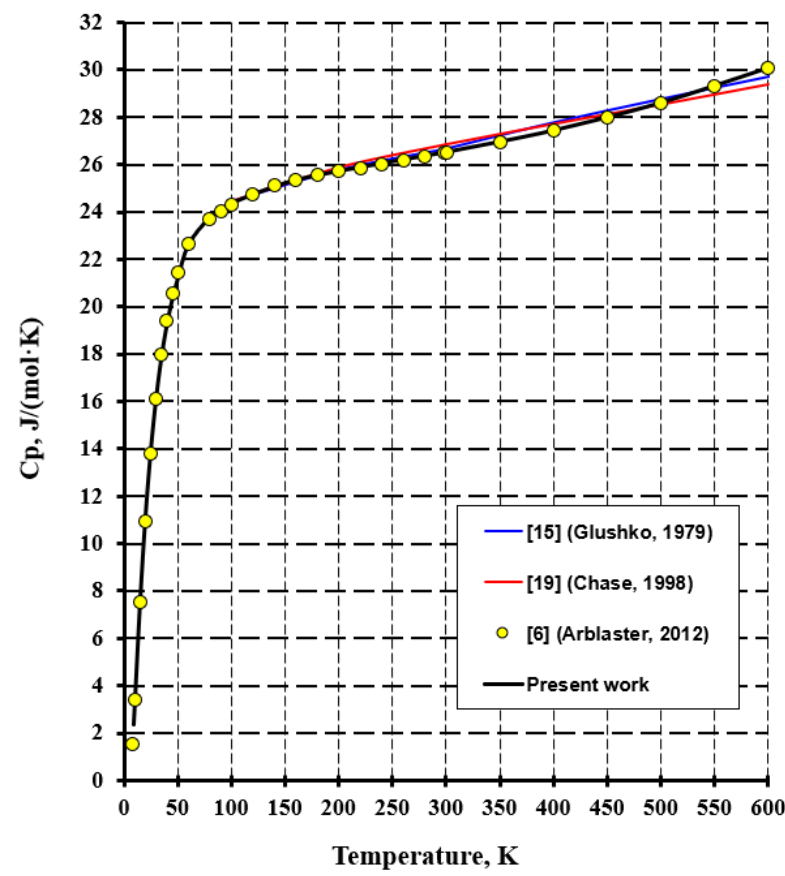

Figure 1. Heat capacity of solid lead. 
Figure 1 displays a calculated heat capacity of the fcc phase of lead when compared with the data from other sources. For solid lead, the relationship derived herein provides a good approximation of the data from the study [6] and is close to the reference data [15,19]. The enthalpy of liquid lead plotted against temperature, as depicted in Figure 2, also reproduces well the data from the studies $[6,15,19]$. It should be noted that the resultant relationship is on a par with the enthalpy measurement results obtained by the resistive pulse-heating technique over a temperature range of 2000-5000 K [104].

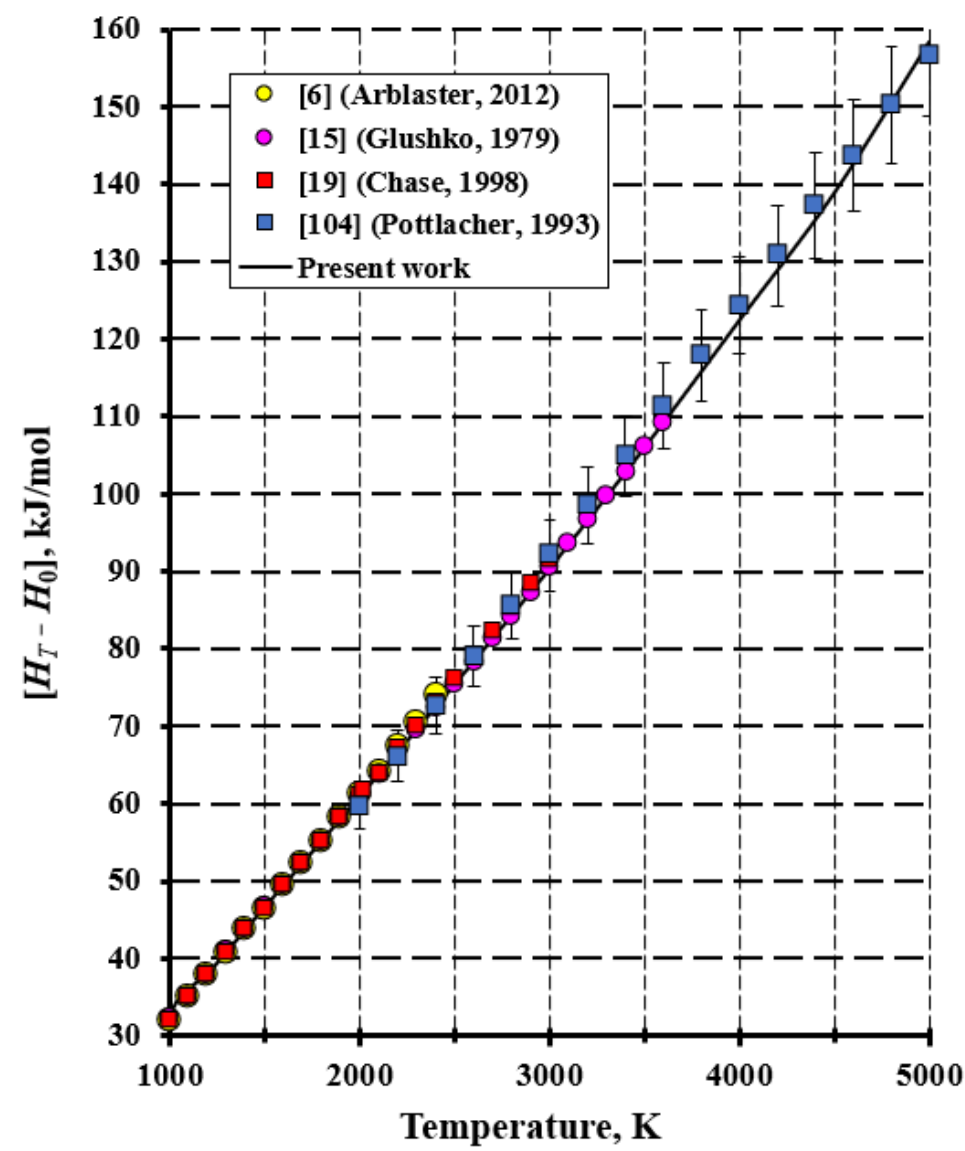

Figure 2. Enthalpy of liquid lead plotted against temperature. The vertical scratch marks indicate an error in the data reported in the literature source [25].

The molar volume and volumetric thermal expansion coefficient (VTEC) of solid lead plotted against temperature are illustrated in Figures 3 and 4. The total number of experimental points was 290 for molar volume and 69 for VTEC. For the molar volume, the mean absolute deviation of calculation from the experiment was $0.0017 \mathrm{~cm}^{3} / \mathrm{mol}$, the mean relative deviation was $0.009 \%$, and the root-mean-square deviation (RMS) was $0.012 \%$. The calculated molar volume of lead at $298.15 \mathrm{~K}$ was $18.2670 \mathrm{~cm}^{3} / \mathrm{mol}$, which is in good agreement with the baseline value (Table 2). The deviations were significantly higher for VTEC, which is due to greater errors in this measure: the mean relative deviation increased two orders of magnitude to $0.92 \%$.

Figure 5 displays the molar volume of $\mathrm{fcc}-\mathrm{Pb}$ plotted against pressure at temperatures of 80,298 , and $396 \mathrm{~K}$. The root-mean-square deviation of the calculated and measured data were $0.14 \%(80 \mathrm{~K}), 0.10 \%(298 \mathrm{~K})$, and $0.14 \%$ (396 K). Table 6 compares the EoS parameters obtained herein with the literature data. 


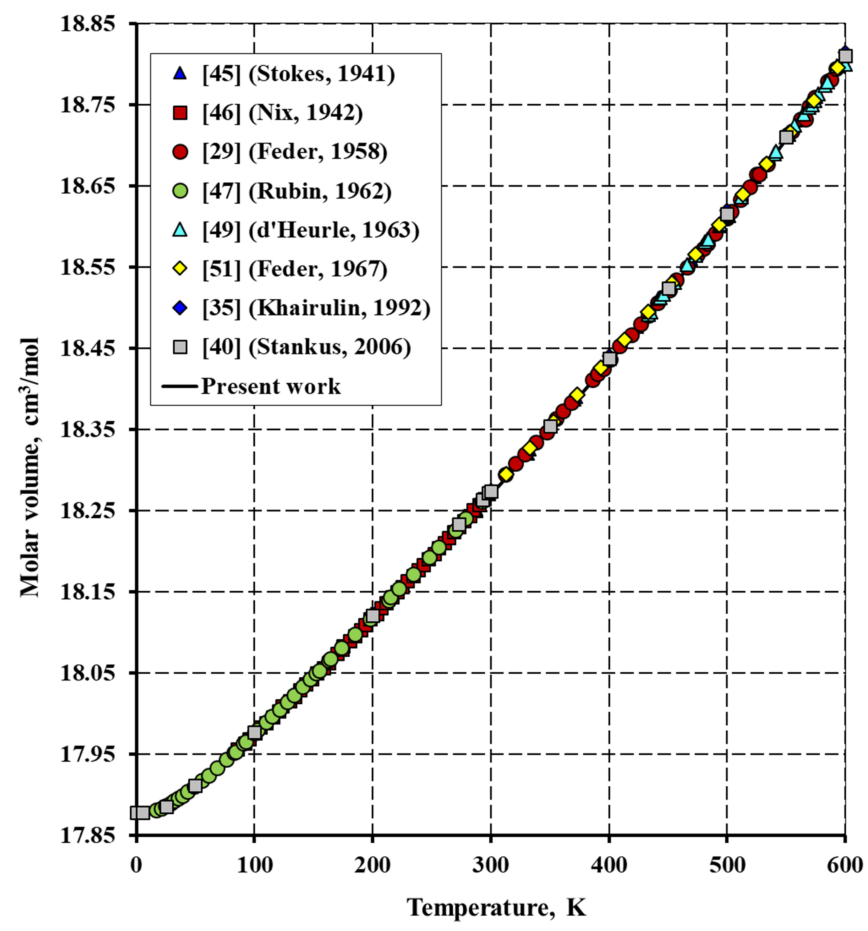

Figure 3. Molar volume of solid lead plotted against temperature.

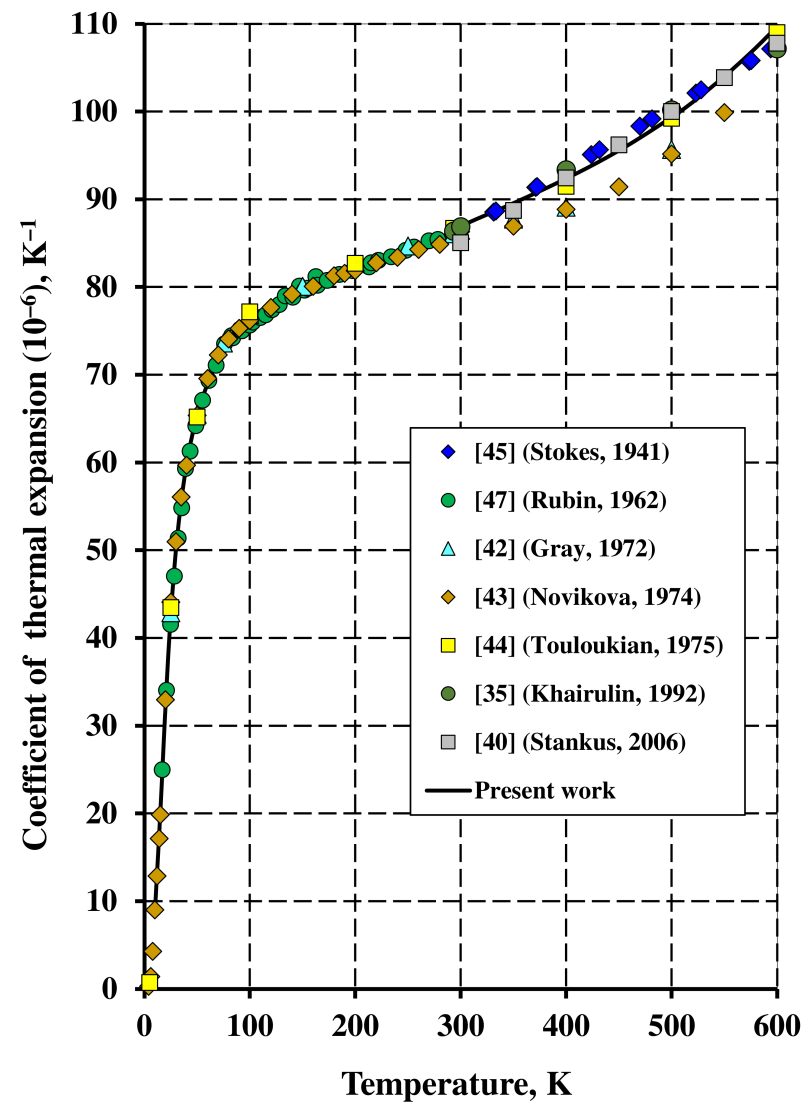

Figure 4. Volumetric thermal expansion coefficient (VTEC) of solid lead plotted against temperature. 


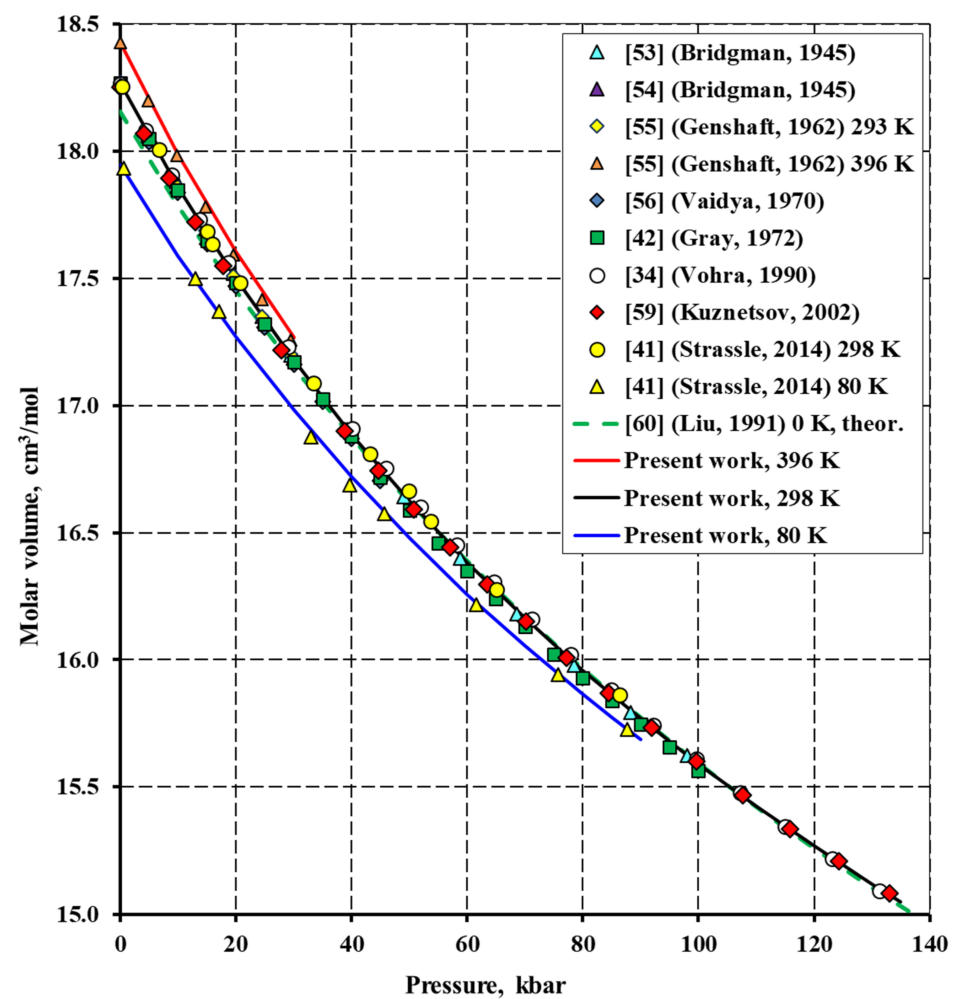

Figure 5. Molar volume of solid lead plotted against pressure at different temperatures.

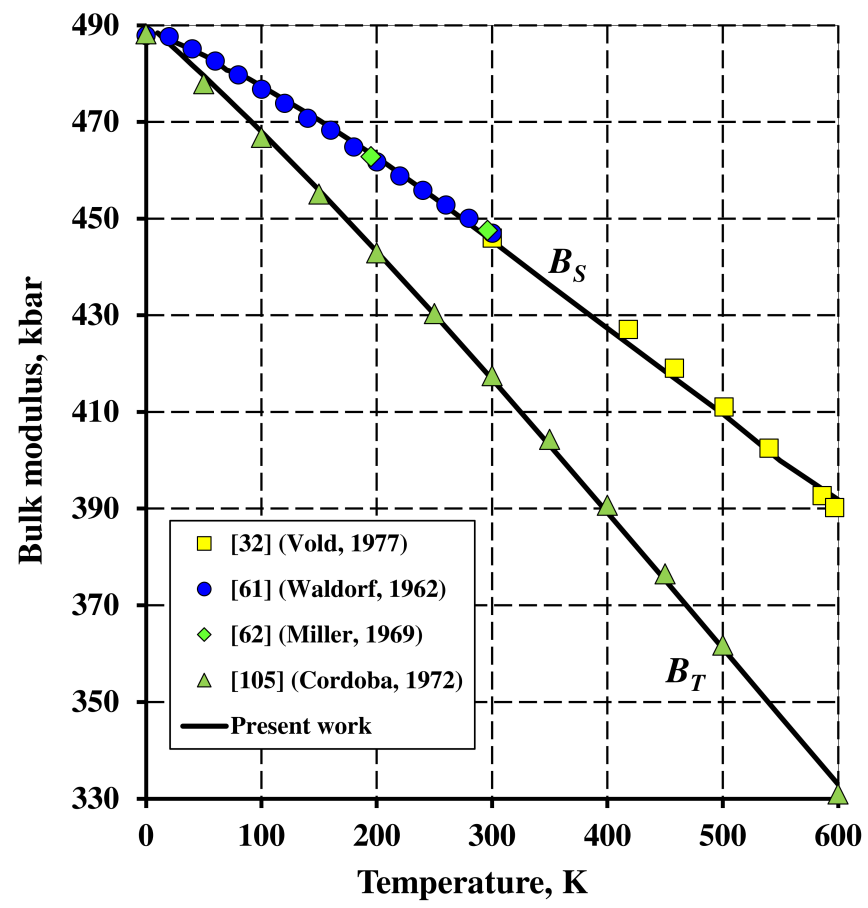

Figure 6. Adiabatic bulk modulus $\left(B_{S}\right)$ and isothermal bulk modulus $\left(B_{T}\right)$ of solid lead plotted against temperature. 


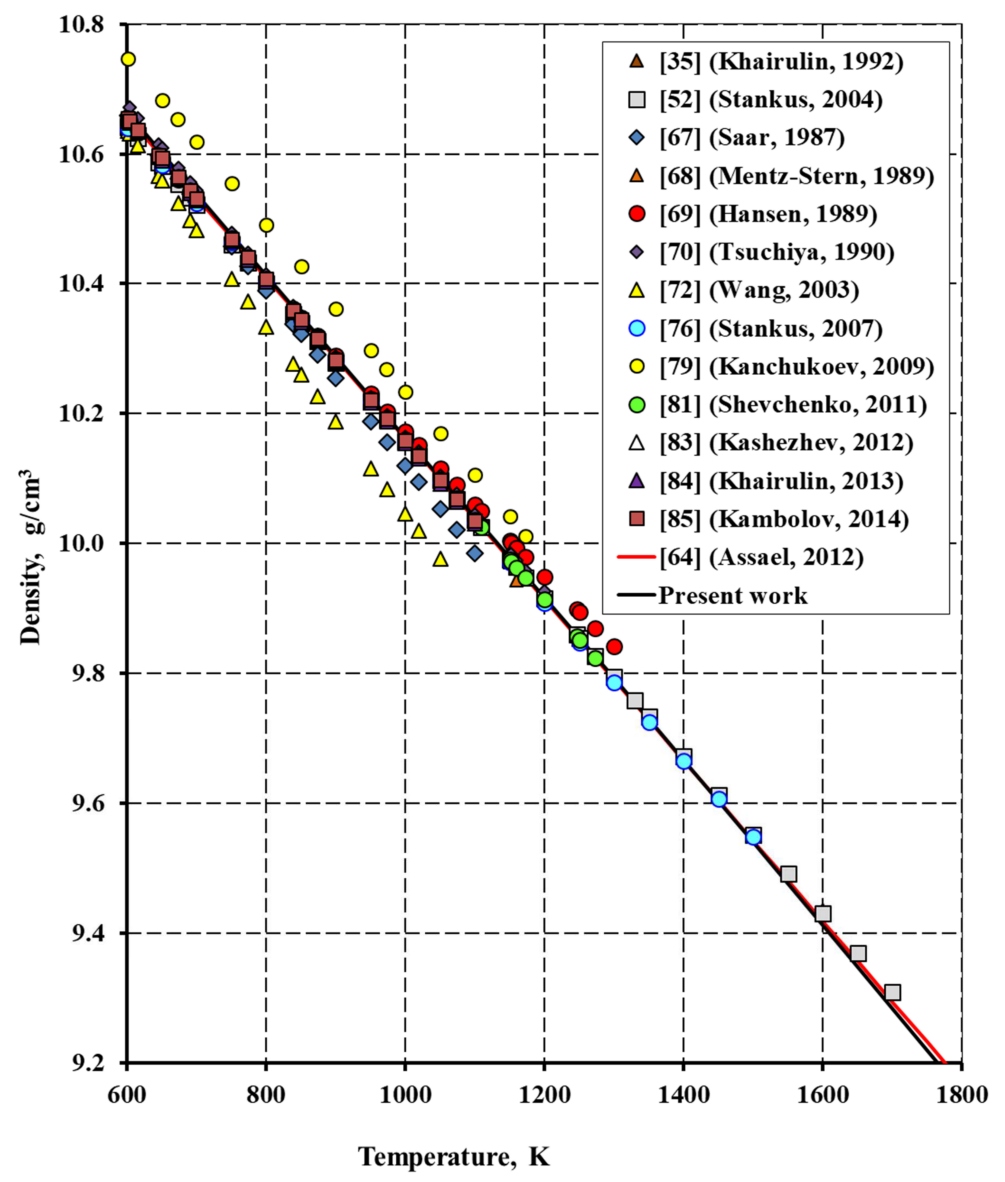

Figure 7. Density of liquid lead as a function of temperature.

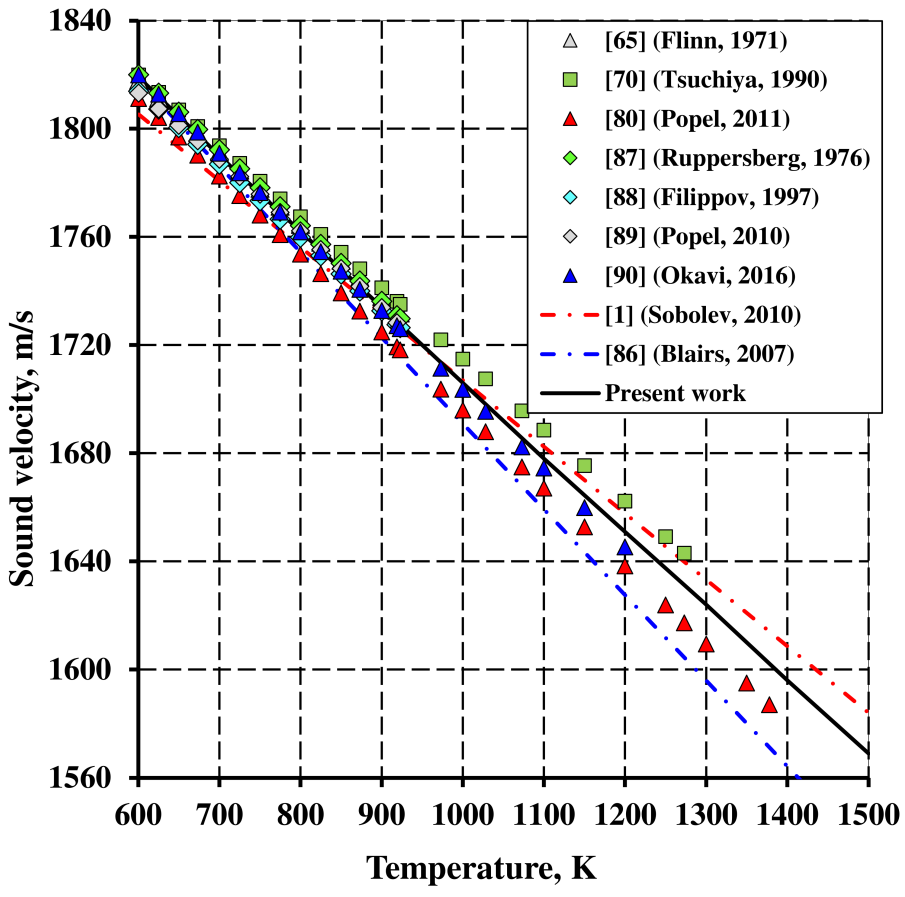

Figure 8. Temperature-dependent sound velocity in liquid lead. 


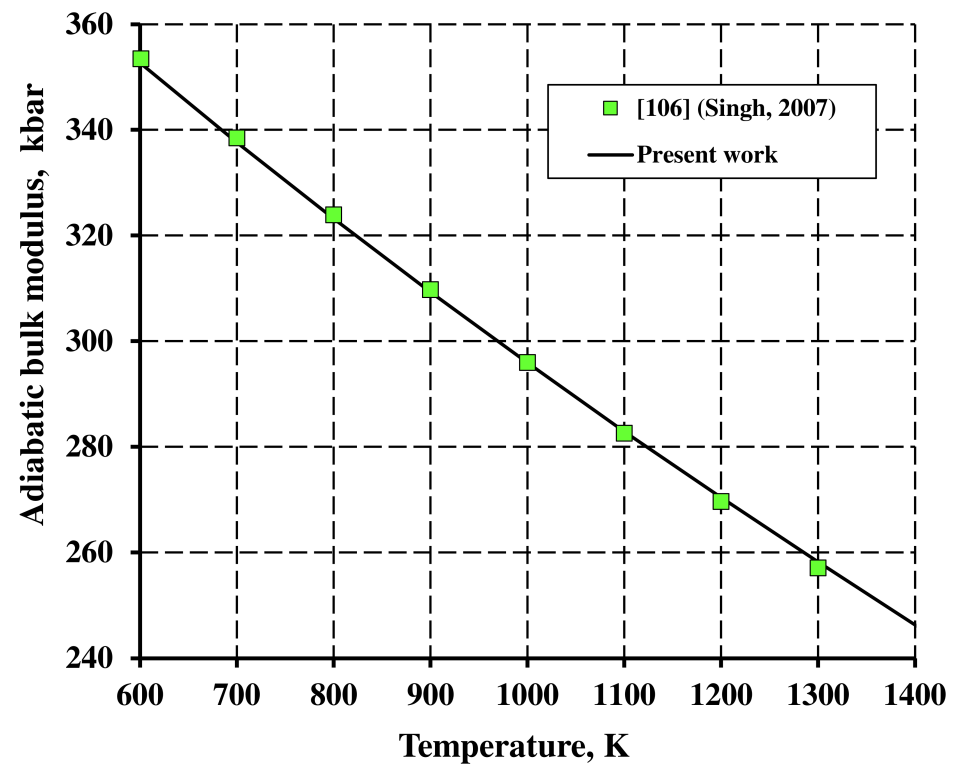

Figure 9. Temperature-dependent adiabatic bulk modulus of liquid lead.

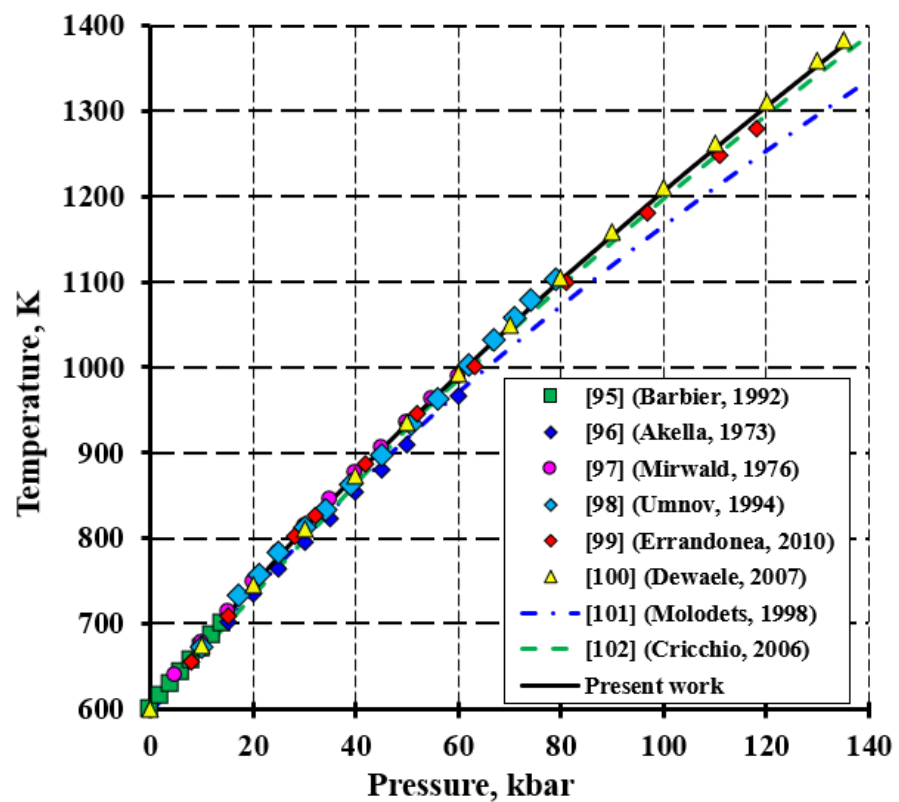

Figure 10. Melting curve of lead.

The differences in bulk compression moduli and their derivatives with respect to pressure for different EoS listed in Table 6 are explained by the conceptually different forms of the equations used, as well as by experimental error (scatter in the data), quantity, and range of the processed data. The greater the data quantity and accuracy, and the wider the pressure range, the more precise the approximation formula for EoS. For instance, a study [56] performed measurements up to $45 \mathrm{kbar}$, while another study [33] performed measurements ranging from 44.2 to $139 \mathrm{kbar}$. In the study by [41], measurements and calculations were performed over a range from 0.3 to $87.4 \mathrm{kbar}$, and the calculated error of the bulk modulus was estimated to be $\pm 20 \mathrm{kbar}$. In this case, different bulk modulus values were obtained even when the same data were treated by different EoS. For instance, in the study [58], the data approximation by different EoS resulted in bulk modulus values that differed by $14 \%$, while the bulk modulus derivative differed by $50 \%$. Therefore, it is more likely that the EoS derived in the present study allows the compressibility of the fcc phase to be described more precisely over a wider pressure range. 
Table 6. Parameters of EoS for the fcc phase of lead.

\begin{tabular}{|c|c|c|c|c|}
\hline$V_{0} * 1\left(\mathrm{~cm}^{3} / \mathrm{mol}\right)$ & $B_{0}$ (kbar) & $n_{0}$ & EoS $* 2$ & Refs. \\
\hline 18.256 & 399.82 & 6.76 & Mur & [56] (Vaidya, 1970) \\
\hline- & 431 & $4.6 \pm 0.3$ & Mur & [57] (Mao, 1977-1978) \\
\hline 18.271 & 399 & $6.13(10)$ & Vinet & [33] (Mao, 1990) \\
\hline 18.263 & 432.0 & 4.87 & BM3 & [34] (Vohra, 1990) \\
\hline 18.156 & 462 & 4.6 & BM3 & [60] (Liu, 1991) \\
\hline \multirow{2}{*}{18.265} & 420 & 6.1 & H11 & \multirow{2}{*}{ [58] (Schulte, 1995) } \\
\hline & 480 & $4 \pm 1$ & H12 & \\
\hline 18.251 & 405 & 5.74 & BM3 & [59] (Kuznetsov, 2002) \\
\hline \multirow{3}{*}{18.2748} & 410.1 & 5.72 & BM3 & \multirow{3}{*}{ [41] (Strassle, 2014) } \\
\hline & 412.5 & 5.72 & Vinet & \\
\hline & 411.3 & 5.72 & HoAp1 & \\
\hline 18.2670 & 417.5 & 5.25 & Tait & Present work \\
\hline
\end{tabular}

Figure 6 illustrates the bulk compression modulus of solid lead plotted against temperature. The dependence obtained in the present study reproduces well the experimental data and is consistent with the isothermal bulk modulus reported [105].

Figure 7 shows the temperature-dependent density of liquid lead when compared with the experimental data from the studies listed in Table 3. It should be noted that the dependence derived herein by optimization of the measured data from 46 studies over a temperature range between lead melting point and $1600 \mathrm{~K}$ almost coincides with that recommended by Assael et al. [64]. The calculated density of liquid lead at its melting point is $10.655 \mathrm{~g} / \mathrm{cm}^{3}$ (the present work), and $10.656 \mathrm{~g} / \mathrm{cm}^{3}$ as reported [64]. The densities at $1600 \mathrm{~K}$ are 9.412 and $9.418 \mathrm{~g} / \mathrm{cm}^{3}$, respectively.

The temperature dependence of the sound velocity in liquid lead obtained herein by optimization of the measured data from 31 studies somewhat differed from the resulting equations adduced in the review papers by $[1,86]$ (Figure 8 ). It should, however, be noted that the calculated temperature-dependent adiabatic bulk modulus of liquid lead depicted in Figure 9 almost matches the data reported in [106].

Figure 10 displays the melting point of lead plotted against pressures of up to $140 \mathrm{kbar}$ when compared with the experimental and calculated data. The calculated melting curve reproduces well the measured data and differs negligibly from the reported one [102].

\section{Conclusions}

The findings presented in this study demonstrate that the model used herein can describe the experimental data available for the fcc phase of solid lead and molten lead over a wide range of pressures and temperatures within experimental uncertainty. Nevertheless, all thermodynamic and thermophysical parameters of solid and liquid lead are mutually agreeable over a pressure range of up to $130 \mathrm{kbar}$ and a temperature range of up to $1400 \mathrm{~K}$, which is due to the melting curve included in the simultaneous co-optimization. The constructed wide-range EoS for liquid lead can be used as the basis for estimation and refinement of properties of the other solid lead phases.

Author Contributions: Conceptualization, investigation, software, writing-original draft preparation, writing - review and editing, supervision, N.V.K.; investigation, V.V.G. All authors have read and agreed to the published version of the manuscript.

Funding: This research was supported by the Ministry of Science and Higher Education of the Russian Federation (agreement No. 075-15-2020-803 with the Zelinsky Institute of Organic Chemistry RAS). 
Data Availability Statement: The raw/processed data required to reproduce these findings are available from the author upon request.

Conflicts of Interest: The authors declare no conflict of interest.

\section{References}

1. Sobolev, V.P. Database of Thermophysical Properties of Liquid Metal Coolants for GEN-IV; Scientific Report SCK CEN-BLG-1069; Belgian Nuclear Research Centre: Mol, Belgium, 2010.

2. Chase, M.W.; Ansara, I.; Dinsdale, A.; Eriksson, G.; Grimvall, G.; Hoglund, H.; Yokokawa, H. Group 1: Heat capacity models for crystalline phases from $0 \mathrm{~K}$ to $6000 \mathrm{~K}$. CALPHAD 1995, 19, 437-447.

3. Voronin, G.F.; Kutsenok, I.B. Universal method for approximating the standard thermodynamic functions of solids. J. Chem. Eng. Data. 2013, 58, 2083-2094. [CrossRef]

4. Jacobson, P.; Stoupin, S. Thermal expansion coefficient of diamond in a wide temperature range. Diam. Relat. Mat. 2019, 97, 107469. [CrossRef]

5. Sobolev, V.P.; Schuurmans, P.; Benamati, G. Thermodynamic properties and equation of state of liquid lead and lead-bismuth eutectic. J. Nucl. Mater. 2008, 376, 358-362. [CrossRef]

6. Arblaster, J.W. Thermodynamic properties of lead. CALPHAD 2012, 39, 47-53. [CrossRef]

7. MacDonald, J.R. Review of some experimental and analytical equations of state. Rev. Modern Phys. 1969, 41, 316-349. [CrossRef]

8. Dymond, J.H.; Malhotra, R. The Tait equation: 100 years on. Int. J. Thermophys. 1988, 9, 941-951. [CrossRef]

9. Hansen, A.R. Volumetric measurements for some liquid metals at high pressures and temperatures. J. Chem. Eng. Data 1991, 36, 252-255. [CrossRef]

10. Dinsdale, A.T. SGTE data for pure elements. CALPHAD 1991, 15, 317-425. [CrossRef]

11. Bedford, R.E.; Bonnier, G.; Maas, H.; Pavese, F. Recommended values of temperature on the International Temperature Scale of 1990 for a selected set of secondary reference points. Metrologia 1996, 33, 133-154. [CrossRef]

12. McLaren, E.H.; Murdock, E.G. The freezing points of high purity metals as precision temperature standards. Can. J. Phys. 1960, 38, 577-587. [CrossRef]

13. Chang, Y.; Oates, W. Materials Thermodynamics; Wiley Series on Processing of Engineering Materials; Wiley: New York, NY, USA, 2010; 320p.

14. Robie, R.A.; Hemingway, B.S.; Fisher, J.R. Thermodynamic Properties of Minerals and Related Substances at 298.15 Kand 1 Bar (105 Pascals) Pressure and at Higher Temperatures; U.S. Geological Survey Bulletin 1452; United States Government Printing Office: Washington, DC, USA, 1978; 456p.

15. Glushko, V. Termodinamicheskie Svoistva Individual'nykh Veshchestv [Thermodynamic Properties of Individual Substances], 3rd ed.; Nauka: Moscow, Russia, 1979; Volume II, Book 2; 344p.

16. Pankratz, L.B.; Stuve, J.M.; Gokcen, N.A. Thermodynamic Data for Mineral Technology; US Bureau of Mines Bulletin 677; United States Government Printing Office: Washington, DC, USA, 1984; 360p.

17. Barin, I. Thermochemical Data of Pure Substances, 3rd ed.; VCH Verlagsgesellschaft mbH: Weinheim, Germany, 1995; 1936p.

18. Robie, R.A.; Hemingway, B.S. Thermodynamic Properties of Minerals and Related Substances at 298.15 K and 1 Bar (105 Pascals) Pressure and at Higher Temperatures; U.S. Geological Survey Bulletin 2131; United States Government Printing Office: Washington, DC, USA, 1995.

19. Chase, M.W. NIST-JANAF Thermochemical Tables, 4th ed.; American Institute of Physics for the National Institute of Standards and Technology: Woodbury, NY, USA, 1998.

20. Sobolev, V. Thermophysical properties of lead and lead-bismuth eutectic. J. Nucl. Mater. 2007, 362, 235-247. [CrossRef]

21. Douglas, T.B.; Dever, J.L. Heat content of lead from 0 to $900^{\circ}$, and the heat of fusion. J. Am. Chem. Soc. 1954, 76, 4824-4826. [CrossRef]

22. Onistchenko, V.P.; Kutirkin, O.F.; Bykov, A.Y. Thermodynamic properties of liquid lead and bismuth at temperatures from the melting points to $2000 \mathrm{~K}$. High Temp. High Press. 1999, 31, 113-118. [CrossRef]

23. Arblaster, J.W. Crystallographic properties of platinum. Platin. Met. Rev. 1997, 41, 12-21. [CrossRef]

24. Owen, E.A.; Yates, E.L. XLI. Precision measurements of crystal parameters. Philos. Mag. 1933, 15, 472-488. [CrossRef]

25. Lu, S.S.; Chang, Y.L. The accurate evaluation of lattice spacings from back-reflection powder photographs. Proc. Phys. Soc. 1941, 53, 517-528. [CrossRef]

26. Klug, H.P. A redetermination of the lattice constant of lead. J. Am. Chem. Soc. 1946, 68, 1493-1494. [CrossRef]

27. Straumanis, M.E. The precision determination of lattice constants by the powder and rotating crystal methods and applications. $J$. App. Phys. 1949, 20, 726-734. [CrossRef]

28. Swanson, H.E.; Tatge, E. Standard X-Ray Diffraction Power Patterns; National Bureau of Standards (US) Circular No. 539; United States Government Printing Office: Washington, DC, USA, 1953; 95p.

29. Feder, R.; Nowick, A.S. Use of thermalal expansion measurements to detect lattice vacancies near the melting point of pure lead and aluminum. Phys. Rev. 1958, 109, 1959-1963. [CrossRef]

30. Takahashi, T.; Mao, H.K.; Bassett, W.A. Lead: X-ray diffraction study of a high-pressure polymorph. Science 1969, 165, 1352-1353. [CrossRef] [PubMed] 
31. Kramer, W.; Nolting, J. Anomale spezifische warmen und fehlordnung der metalle indium, zinn, blei, zink, antimon und aluminium. Acta Metall. 1972, 20, 1353-1359. [CrossRef]

32. Vold, C.L.; Glicksman, M.E.; Kammer, E.W.; Cardinal, L.C. The elastic constants for single-crystal lead and indium from room temperature to the melting point. J. Phys. Chem. Solids 1977, 38, 157-160. [CrossRef]

33. Mao, H.K.; Wu, Y.; Shu, J.F.; Hu, J.Z.; Hemley, R.J.; Cox, D.E. High-pressure phase transition and equation of state of lead to 238 GPa. Solid State Commun. 1990, 74, 1027-1029. [CrossRef]

34. Vohra, Y.K.; Ruoff, A.L. Static compression of metals Mo, Pb, and Pt to 272 GPa: Comparison with shock data. Phys. Rev. B 1990, 42, 8651-8654. [CrossRef]

35. Khairulin, R.; Stankus, S. Termicheskie svoistva svintsa i aliuminiia v tverdom i zhidkom sostoianiiakh [Thermal properties of lead and aluminum in solid and liquid states]. In Teplofizicheskie Svoistva Rastvorov, Rasplavov i Kompozitov [Ther-Mophysical Properties of Solutions, Melts and Composites]; Institut Teplofiziki Sibirskogo Otdeleniia Akademii nauk USSR: Novosibirsk, Russia, 1992; pp. 13-24. (In Russian)

36. Trunin, R.F. Experimental Data on Shock Compression and Adiabatic Expansion of Condensed Matter; RNFC-VNIIEF: Sarov, Russia, 2001; 446p. (In Russian)

37. Bogoslovskaya, G.P.; Kirillov, P.L.; Kupitz, J.; Heusener, G.; Nishi, Y.; Rineiskii, A.; Stanculescu, A.; Wade, D.; Yarovitsin, V.V Comparative Assessment of Thermophysical and Thermohydraulic Characteristics of Lead, Lead-Bismuth and Sodium Coolants for Fast Reactors; IAEA: Vienna, Austria, 2002; 65p.

38. Lubarda, V.A. On the effective lattice parameter of binary alloys. Mech. Mat. 2003, 35, 53-68. [CrossRef]

39. Rothman, S.D.; Davis, J.-P.; Maw, J.; Robinson, C.M.; Parker, K.; Palmer, J. Measurement of the principal isentropes of lead and lead-antimony alloy to $\sim 400 \mathrm{kbar}$ by quasi-isentropic compression. J. Physics D. App. Phys. 2005, 38, 733-740. [CrossRef]

40. Stankus, S.V.; Khairulin, R.A. The density of alloys of tin-lead system in the solid and liquid states. High Temp. 2006, 44, 389-395. [CrossRef]

41. Strassle, T.; Klotz, S.; Kunc, K.; Pomjakushin, V.; White, J.S. Equation of state of lead from high-pressure neutron diffrac-tion up to 8.9 GPa and its implication for the $\mathrm{NaCl}$ pressure scale. Phys. Rev. B 2014, 90, 014101. [CrossRef]

42. Gray, D.E. American Institute of Physics Handbook, 3rd ed.; McGraw-Hill: New York, NY, USA, 1972.

43. Novikova, S. Teplovoe Rasshirenie Tverdykh Tel [Thermal Expansion of Solids]; Nauka: Moscow, Russia, 1974; 293p. (In Russian)

44. Touloukian, Y.S.; Kirby, R.K.; Taylor, R.E.; Desai, P.D. Thermal expansion metallic elements and alloys. In Thermophysical Properties of Matter; The TPRC Data Series; IFI/Plenum: New York, NY, USA, 1975; 1440p.

45. Stokes, A.R.; Wilson, A.J.C. The thermal expansion of lead from $0{ }^{\circ} \mathrm{C}$ to $320^{\circ} \mathrm{C}$. Proc. Phys. Soc. 1941, 53, 658-662. [CrossRef]

46. Nix, F.C.; MacNair, D. The thermal expansion of pure metals. II: Molybdenum, palladium, silver, tantalum, tungsten, plati-num, and lead. Phys. Rev. 1942, 6, 74-78. [CrossRef]

47. Rubin, T.; Johnston, L.; Altman, H.W. The thermal expansion of lead. J. Phys. Chem. 1962, 66, 266-268. [CrossRef]

48. White, G.K. Thermal expansion at low temperatures. IV. Normal and superconducting lead. Philos. Mag. 1962, 7, 271-278. [CrossRef]

49. D'Heurle, F.M.; Feder, R.; Nowick, A.S. Equilibrium concentration of lattice vacancies in lead and lead alloys. J. Phys. Soc. Japan 1963, 18, 184-190.

50. Channing, D.A.; Weintroub, S. Thermal expansion of lead at low temperatures. Can. J. Phys. 1965, 43, 955-959. [CrossRef]

51. Feder, R.; Nowick, A.S. Equilibrium vacancy concentration in pure Pb and dilute Pb-Tl and Pb-In alloys. Philos. Mag. 1967, 15, 805-812. [CrossRef]

52. Stankus, S.V.; Khairulin, R.A.; Mozgovoi, A.G.; Roshchupkin, V.V.; Pokrasin, M.A. Plotnost' svintsa v tverdoi i zhidkoi fazakh pri temperaturakh 300-1800 K [The density of lead in solid and liquid phases at temperatures of 300-1800 K]. Perspekt. Mater. 2004, 6, 30-35. (In Russian)

53. Bridgman, P.W. The compression of twenty-one halogen compounds and eleven other simple substances to $100,000 \mathrm{~kg} / \mathrm{cm}$. Proc. Am. Acad. Arts Sci. 1945, 76, 1-7. [CrossRef]

54. Bridgman, P.W. The compression of sixty-one solid substances to $25,000 \mathrm{~kg} / \mathrm{cm} 2$, determined by a new rapid method. Proc. Am. Acad. Arts Sci. 1945, 76, 9-24.

55. Genshaft, I.S.; Livshits, L.D.; Riabinin, I.N. Opredelenie parametrov sostoianiia tverdykh tel pri vysokikh davleniiakh metodom smeshcheniia porshnia [Determination of the parameters of the state of solids at high pressures by the piston displacement method]. Prikl. Mekhanika Tekhnicheskaia Fiz. 1962, 5, 107-116. (In Russian)

56. Vaidya, S.N.; Kennedy, G.C. Compressibility of 18 metals to 45 kbar. J. Phys. Chem. Solids 1970, 31, $2329-2345$.

57. Mao, H.; Bell, P. Study of lead at high pressure: Compressibility and fixed-point transition between the FCC and HCP polymorphs under various degrees of nonhydrostatic stress. In Carnegie Institution of Washington; Year Book 77; Carnegie Institution of Washington: Washington, DC, USA, 1977-1978; pp. 842-848.

58. Schulte, O.; Holzapfel, W.B. Equation-of-state behavior for different phases of lead under strong compression. Phys. Rev. B 1995, 52, 12636-12639. [CrossRef]

59. Kuznetsov, A.; Dmitriev, V.; Dubrovinsky, L.; Prakapenka, V.; Weber, H.P. FCC-HCP phase boundary in lead. Solid State Commun. 2002, 122, 125-127. [CrossRef]

60. Liu, A.Y.; Garcia, A.; Cohen, M.L.; Godwal, B.K.; Jeanloz, R. Theory of high-pressure phases of Pb. Phys. Rev. B 1991, 43, 1795-1798. [CrossRef] 
61. Waldorf, D.L.; Alers, G.A. Low-temperature elastic moduli of lead. J. App. Phys. 1962, 33, 3266-3269. [CrossRef]

62. Miller, R.A.; Schuele, D.E. The pressure derivatives of the elastic constants of lead. J. Phys. Chem. Solids 1969, 30, 589-600. [CrossRef]

63. Pashaev, B.P.; Palchaev, D.K.; Pashchuk, E.G.; Revelis, V.G. Plotnost', skorost' ul'trazvuka, elektro- i teploprovodnost' legkoplavkikh mnogovalentnykh metallov v zhidkom sostoianii [Density, ultrasound velocity, electrical and thermal conductivity of low-melting multivalent metals in the liquid state]. Obz. Teplofiz. Svoistvam Veshchestv 1982, 3, 1-106. (In Russian)

64. Assael, M.J.; Kalyva, A.E.; Antoniadis, K.D.; Banish, R.M.; Egry, I.; Wu, J.; Kaschnitz, E.; Wakeham, W.A. Reference data for the density and viscosity of liquid antimony, bismuth, lead, nickel and silver. High Temp.-High Press. 2012, 41, 161-184.

65. Flinn, J.M.; Jarzynski, J.; Litovitz, T.A. Mechanism of volume viscosity in molten bismuth and lead. J. Chem. Phys. 1971, 54, 4331-4340. [CrossRef]

66. Schwaneke, A.E.; Falke, W.L.; Miller, V.R. Surface tension and density of liquid tin-lead solder alloys. J. Chem. Eng. Data 1978, 23, 298-301. [CrossRef]

67. Saar, J.; Ruppersberg, H. Calculation of $\mathrm{C}_{P}(T)$ for liquid $\mathrm{Li} / \mathrm{Pb}$ alloys from experimental $\rho(T)$ and $(d P / d T)_{S}$ data. J. Phys. F. Met. Phys. 1987, 17, 305-314. [CrossRef]

68. Mentz-Stern, R.; Hoheisel, C. Static and dynamic properties of liquid lead computed by molecular dynamics. Phys. Rev. A 1989, 40, 4558-4563. [CrossRef]

69. Hansen, A.R.; Kaminski, M.A.; Lira, C.T.; Eckert, C.A. Volumes and excess volumes of some liquid metals and alloys. Ind. Eng. Chem. Res. 1989, 28, 97-104. [CrossRef]

70. Tsuchiya, Y. Molar volume of the liquid Pb-Te system. J. Phys. Soc. Japan 1990, 59, 207-212. [CrossRef]

71. Hansen, A.R.; Kaminski, M.A.; Eckert, C.A. Molar and excess volume of liquid In-Sb, Mg-Sb, and Pb-Sb alloys. J. Chem. Eng Data 1990, 35, 153-156. [CrossRef]

72. Wang, L.; Wang, Q.; Xian, A.; Lu, K. Precise measurement of the densities of liquid Bi, Sn, Pb and Sb. J. Condens. Matter. Phys. 2003, 15, 777-783. [CrossRef]

73. Alchagirov, B.B.; Mozgovoi, A.G.; Kurshev, O.I. Experimental determination of the density of melted lead and bismuth at temperatures up to 800 K. Russ. J. Phys. Chem. 2003, 77, 1553-1554.

74. Alchagirov, B.B.; Mozgovoi, A.G.; Shamparov, T.M. Plotnost' rasplavlennogo svintsa pri vysokikh temperaturakh [Density of molten lead at high temperatures]. Perspekt. Mater. 2003, 5, 53-57. (In Russian)

75. Kurshev, O.I. Plotnost', Poverkhnostnoe Natiazhenie i Rabota Vykhoda Elektrona Legkoplavkikh Metallov i Splavov [Density, Surface Tension and Electron Output Operation of Low-Melting Metals and Alloys]. Ph. D. Thesis, Kabardino-Balkarian State University, Nalchik, Russia, 2005; 20p. (In Russian)

76. GSSD 229-07; The Density of Lead, Bismuth and Their Eutectic Alloy in the Condensed State in the Temperature Interval of 273,15 ... $1500 \mathrm{~K}$, Metrology and Conformity Assessment. Metrology and Conformity Assessment; Russian Scientific and Technical Center for Standardization: Moscow, Russia, 2007.

77. Alchagirov, B.B.; Mozgovoi, A.G.; Taova, T.M.; Khokonov, K.B. Eksperimental'noe issledovanie plotnosti zhidkikh galliia, indiia, vismuta i svintsa pri temperaturakh do $500{ }^{\circ} \mathrm{C}$ [Experimental study of the density of liquid gallium, indium, bismuth and lead at temperatures up to $500^{\circ} \mathrm{C}$ ]. Perspekt. Mater. 2007, 3, 33-36. (In Russian).

78. Khairulin, R.A.; Stankus, S.V. The concentration dependences of molar volume, thermal expansion coefficient, and interdif-fusion coefficient for liquid lead-magnesium system. J. Nucl. Mater. 2008, 377, 501-505. [CrossRef]

79. Kanchukoev, V.Z.; Ponezhev, M.K.; Sozaeva, A.B.; Sozaev, V.A. Polytherms of surface tension and density of melts of lead-lithium system. High Temp. 2009, 47, 292-295. [CrossRef]

80. Popel, P.; Stankus, S.; Mozgovoy, A.; Khairulin, R.; Pokrasin, M.; Yagodin, D.; Konstantinova, N.; Borisenko, A.; Guzachev, M. Physical properties of heavy liquid-metal coolants in a wide temperature range. EPJ Web of Conf. 2011, 15, 01014. [CrossRef]

81. Shevchenko, V.G.; Chentsov, V.P.; Kiselev, A.I.; Mozgovoi, A.G. Plotnost' i poverkhnostnoe natiazhenie rasplavov sistemy gallii-svinets [Density and surface tension of melts of the gallium-lead system]. Rasplavy 2011, 4, 47-52. (in Russian).

82. Chentsov, V.P.; Mozgovoi, A.G.; Shevchenko, V.G.; Kiselev, A.I. Density and surface tension polytherms of gallium-lead melts. High Temp. 2012, 50, 38-43. [CrossRef]

83. Kashezhev, A.Z.; Kutuev, R.A.; Ponezhev, M.K.; Sozaev, V.A.; Khasanov, A.I. Density and surface tension polyterms of lead-based alloys. Bull. Russ. Acad. Sci. Phys. 2012, 76, 791-793. [CrossRef]

84. Khairulin, R.A.; Stankus, S.V. Density of liquid and solid Mg-Pb alloys. J. Eng. Thermophys. 2013, 22, 7-19. [CrossRef]

85. Kambolov, D.A.; Kashezhev, A.Z.; Kutuev, R.A.; Ponezhev, M.K.; Sozaev, V.A.; Shermetov, A.K. Polytherms of density and surface tension of bismuth lead and of angle of wetting of high-nickel and ferritic-martensitic steels by the Pb-Bi alloy. High Temp. 2014 52, 381-384. [CrossRef]

86. Blairs, S. Review of data for velocity of sound in pure liquid metals and metalloids. Int. Mat. Rev. 2007, 52, 321-344. [CrossRef]

87. Ruppersberg, H.; Speicher, W. Density and compressibility of liquid Li-Pb alloys. Z. Naturforschung 1976, 31a, 47-52. [CrossRef]

88. Filippov, V.V.; Popel, P.S. Sound velocity and compressibility of Ga-Pb liquid alloys. J. Chim. Phys. 1997, 94, 1152-1158. [CrossRef]

89. Popel', P.S.; Yagodin, D.A.; Mozgovoi, A.G.; Pokrasin, M.A. An experimental investigation of the velocity of sound in molten lead and bismuth and in their reciprocal eutectic alloy at high temperatures. High Temp. 2010, 48, 181-187. [CrossRef]

90. Okavi, S.; Emuna, M.; Greenberg, Y.; Yahel, E.; Makov, G. Interactions in liquid bismuth-lead from sound velocity studies. J. Mol. Liq. 2016, 220, 788-794. [CrossRef] 
91. Hixson, R.S.; Winkler, M.A.; Shaner, J.W. Improvements to the isobaric expansion experiment and recent results for lead. High Temp. High Press. 1985, 17, 267-270.

92. Grosse, A.V.; Kirshenbaum, A.D. The temperature range of liquid lead and silver and an estimate of their critical constants. $J$ Inorg. Nucl. Chem. 1962, 24, 739-748. [CrossRef]

93. Bean, V.E.; Akimoto, S.; Bell, P.M.; Block, S.; Holzapfel, W.B.; Manghnani, M.H.; Nicol, M.F.; Stishov, S.M. Another step to-ward an international practical pressure scale. Phys. $B+C$ 1986, 139-140, 52-54. [CrossRef]

94. McDaniel, M.L.; Babb, S.E.; Scott, G.J. Melting curves of five metals under high pressure. J. Chem. Phys. 1962, 37, 822-828. [CrossRef]

95. Barbier, P.; Gelon, J.L.; Robert, J. Melting curves of Bi, Pb and $\mathrm{Al}$ using microdifferential thermal analysis up to $1.4 \mathrm{GPa}$. High Press. Res. 1992, 10, 465-468. [CrossRef]

96. Akella, J.; Ganguly, J.; Grover, R.; Kennedy, G. Melting of lead and zinc to 60 kbar. J. Phys. Chem. Solids 1973, 34, 631-636. [CrossRef]

97. Mirwald, P.W.; Kennedy, G.C. Melting temperature of lead and sodium at high pressures. J. Phys. Chem. Solids 1976, 37, 795-797. [CrossRef]

98. Umnov, A.G.; Brazhkin, V.V.; Voloshin, R.N. The method of volumetric measurements under high pressure. II. Quantitative measurements. High Press. Res. 1994, 13, 61-64. [CrossRef]

99. Errandonea, D. The melting curve of ten metals up to $12 \mathrm{GPa}$ and $1600 \mathrm{~K}$. J. App. Phys. 2010, 108, 1-10. [CrossRef]

100. Dewaele, A.; Mezouar, M.; Guignot, N.; Loubeyre, P. Melting of lead under high pressure using second-scale time-resolved X-ray diffraction. Phys. Rev. B 2007, 76, 1-5. [CrossRef]

101. Molodets, A.M.; Molodets, M.A.; Nabatov, S.S. Isochoric-isothermal potential of liquid metals. High Temp. 1998, 36, 891-896.

102. Cricchio, F.; Belonoshko, A.B.; Burakovsky, L.; Preston, D.L.; Ahuja, R. High-pressure melting of lead. Phys. Rev. B 2006, 73, 1-4. [CrossRef]

103. Nelder, J.A.; Mead, R. A simplex method for function minimization. Comput. J. 1965, 7, 308-313. [CrossRef]

104. Pottlacher, G.; Kaschnitz, E.; Jager, H. Investigations of thermophysical properties of liquid metals with a rapid resistive heating technique. J. Non-Cryst. Solids 1993, 156-158, 374-378. [CrossRef]

105. Cordoba, G.; Brooks, C.R. The heat capacity of lead from 300 to 850 K. Conversion of CP to CV for solid lead. Phys. Status Solidi A 1972, 11, 749-754. [CrossRef]

106. Singh, R.N.; Arafin, S.; George, A.K. Temperature-dependent thermo-elastic properties of s-, p- and d-block liquid metals. Phys. $B$ Condens. Matter. 2007, 387, 344-351. [CrossRef] 